\title{
SISTEMAS DE VERIDICÇÃO E A PREVISIBILIDADE DE DESDOBRAMENTOS POLITICOS EM MOMENTOS DE CRISE: LEITURAS A PARTIR DE UMA CENA DE TRISTES TRÓPICOS ${ }^{1}$
}

Renato Albuquerque de Oliveira ${ }^{2}$

RESUMO: Neste artigo tenta-se trabalhar uma questão político-veridictória contida em Tristes trópicos, de Lévi-Strauss. A ideia é pensar em como uma cena de crise contida no livro nos permite refletir sobre o político entre os Nambiquara - um povo ameríndio - e como essa reflexão pode ser um estímulo a pensar o político em outras sociedades, como a brasileira como um todo, especialmente a respeito de questóes sobre a veridicção. $\mathrm{O}$ desenvolvimento aqui realizado tomará por base reflexóes vindas da antropologia política de Pierre Clastres, além de ser construído levando em conta as propostas da semiótica estruturalista, especialmente como formuladas por Algirdas Julien Greimas e Claude Zilberberg. Assim, espera-se realizar uma tentativa de contribuição para a compreensão de sistemas político-veridictórios por meio de uma aproximaçáo da semiótica como leitura para os objetos analisáveis pelas ciências humanas.

PALAVRAS-CHAVE: Tristes trópicos. Sistemas político-veridictórios. Antropologia política. Semiótica.

\section{SYSTEMS OF VERIDICTION AND THE PREDICTABILITY OF POLITICAL DEVELOPMENTS IN TIMES OF CRISIS: READINGS FROM A SCENE IN TRISTES TROPIQUES}

ABSTRACT: In this paper we try to work on a political-veridictional issue in Lévi-Strauss's Tristes Tropiques book. The idea here is to think about how a scene contained in this book allows us to reflect on the political among the Nambiquara - an Amerindian nation - and

\footnotetext{
1 A pesquisa desenvolvida pelo autor recebe apoio da CAPES.

2 Universidade de São Paulo (USP), Faculdade de Filosofia, Letras e Ciências Humanas, São Paulo - SP - Brasil. Mestrando em Semiótica no Programa de Pós-Graduação em Semiótica e Linguística Geral. Orcid: https://orcid. org/0000-0002-9114-4004. renato.ao@usp.br.
} 
how this reflection can be stimulant to think about the political in other societies, such as the Brazilian one, as a whole, especially about issues that concern veridiction. The development here will be based on reflections of the political anthropology of Pierre Clastres, besides being built considering the proposals of structuralist semiotics, especially as formulated by Algirdas Julien Greimas and Claude Zilberberg. Thus, it is expected to make an attempt to contribute to the understanding of political-veridictory systems through an approximation of Semiotics as a way to conceive the objects analysable by the human sciences.

KEYWORDS: Tristes tropiques. Political-veridictory systems. Political anthropology. Semiotics.

\section{Da importância da veridicção na política}

A maneira como o processo veridictório se desenvolve atualmente na política brasileira tem sido estímulo para que se busque compreender como a narrativa dominante conseguiu se estabelecer e tem se reproduzido, mesmo com todas as questóes problemáticas que a atual administração pública, principalmente na esfera executiva federal, tem nos mostrado. $\mathrm{O}$ uso das fake news são exemplo-mor de construçóes de verdades nesse meandro do político. Esse processo veridictório, nos parece, possui correspondência a um sistema veridictório. Se o sintagma é visto no desenvolvimento processual das fake news, provavelmente seu paradigma seria observado a partir de derivaçóes estruturais contidas na cultura, especialmente em seus meandros políticos. Partindo dessas premissas, acreditamos que uma maneira inicial de desenvolver essa proposta - como a dependência sintagma-paradigma acontece na política e sua relação com a veridicção - pode ser vista na realização de comparação entre diferentes sistemas político-veridictórios. Levando isso em conta, pensaremos sobre uma ação política que aconteceu entre os Nambiquara, povo ameríndio que habita território localizado entre os estados de Mato Grosso e Rondônia, ação descrita e comentada por Lévi-Strauss em Tristes trópicos. Tentaremos, então, observar se há algum elemento possível de ser encarado como característico do sistema político-veridictório desse povo e que possa servir de estímulo a uma reflexão sobre o nosso próprio sistema político-veridictório.

\section{Escrever sem significar}

"O testemunho da escrita só tem valor com a condição de ser interpretado".

(SAUSSURE, 2012 [1916], p. 68). 
Imagine-se como um etnólogo tentando recensear uma população indígena. Considere que a obtenção dessa informação seja importante para a elaboração de sua etnografia. Uma estratégia para isso: propor a um chefe indígena que chame grupos de diferentes lugares para uma reunião. Sua estratégia funciona. Um dos motes que possibilitaram a reunião desses grupos foi a esperança que tiveram em receber presentes vindos de você, etnólogo, pois é bastante comum no mundo ameríndio - quiçá uma regra mínima nesse tipo de interação - que um anfitriāo trate assim seus convidados. Acontece algo parecido com LéviStrauss entre os Nambiquara. Estando ele, enfim, em reuniáo com diferentes grupos deste povo, um "incidente extraordinário", como chama, desenrola-se. A seguir, vale lermos suas palavras sobre esse momento, contado no capítulo "Lição de escrita”, em Tristes trópicos:

É de imaginar que os Nambiquara não sabem escrever; mas tampouco desenham, com exceção de alguns pontilhados ou zigue-zagues nas suas cuias. Porém, da mesma maneira como agi com os Cadiueu [outro povo ameríndio que visitara], distribuí folhas de papel e lápis com os quais, de início, nada fizeram; depois, certo dia vi-os muito atarefados em traçar no papel linhas horizontais onduladas. Que queriam fazer, afinal? Tive de me render à evidência: escreviam, ou, mais exatamente, procuravam dar a seu lápis o mesmo uso que eu, o único que então podiam conceber, pois eu ainda não tentara distraí-los com meus desenhos. Para a maioria, o esforço parava por aí; mas o chefe do bando enxergava mais longe. Era provável que só ele tivesse compreendido a função da escrita. Assim, exige de mim um bloco e nos equipamos da mesma forma quando trabalhamos juntos. Não me comunica verbalmente as informaçóes que lhe peço, mas traça no seu papel linhas sinuosas e me mostra, como se ali eu devesse ler a sua resposta. Ele próprio se deixa tapear um pouco com a sua encenação; toda vez que sua mão termina uma linha, examina-a ansioso como se dela devesse surgir algum significado, e a mesma desilusão se estampa em seu rosto. Mas não a admite; e está tacitamente combinado entre nós que a sua garatuja tem um sentido que finjo decifrar; o comentário verbal segue-se quase de imediato e dispensa-me de exigir os esclarecimentos necessários (LÉVI-STRAUSS, 2016, p. 315-316).

Note que o chefe desse grupo foi o único que aparentemente compreendeu a função da escrita. A chefia ameríndia possui um estatuto bastante particular, importante de ser elucidado para desenvolvermos a reflexáo que aqui propomos. 
Não é possível que simplesmente a homologuemos a nossos critérios de chefia, vagos que sejam. Por isso, antes de falarmos da importância na relação desse chefe Nambiquara com a compreensão da função da escrita que tivera, precisamos primeiro termos uma ideia do que é, em linhas gerais, um chefe ameríndio.

\section{Um chefe que deve e não pode}

A obra de Pierre Clastres apresentou ideias importantes para que algumas questóes a respeito da política ameríndia fossem compreendidas. Uma de suas contribuiçóes foi realizar uma guinada epistemológica a respeito de como o político, no mundo ameríndio, poderia ser encarado: o lugar comum da reflexão antropológica sobre esse assunto, até então, guiado por forças etnocêntricas, pensava as populaçóes indígenas a partir de seu próprio parâmetro político e que desembocavam, em geral, em um comentário sobre a falta ou a incompletude do modelo estatal nestes povos. Nesse sentido, sugere não mais pensar o poder político a partir do parâmetro ocidental, mas pensá-lo, nesses outros grupos humanos, a partir de sua imanência: não pensá-lo pela falta de um mecanismo como aos moldes do que chamamos Estado, mas pela existência de algo particular que torne o exercício do poder político possível entre esses povos (CLASTRES, 2013). Levando isso em conta e a partir de um refinamento de ideias propostas por Robert Lowie, baseadas em uma reflexão sobre dados etnográficos de diferentes populaçóes ameríndias, Clastres sugere que o chefe ameríndio não seria "tão chefe" assim, embora estivesse em um papel social de destaque. Para ele, as características gerais de um chefe ameríndio, diferentemente das de um chefe ocidental, colocariam-no como aquele que:

[...] ocupa um lugar de poder, sem jamais exercê-lo, e ele não o faz justamente porque é tido como prisioneiro do grupo que deve, por assim dizer, representar. Essa prisão explica-se também pela dívida que ele contrai: ao ser imbuído de certos privilégios, como a poliginia, vê-se obrigado a servir aos seus com dádivas frequentes e também com uma eloquência sagaz, plena de valor mas destituida de uma capacidade de mando (SZTUTMAN, 2012, p. 46, grifo nosso).

Repare que esse chefe deve representar seu grupo, além de o servir com dádivas frequentes e de náo ter poder de mando. O momento da cena contada por Lévi-Strauss nos mostra um pouco dessas atribuiçóes do chefe ameríndio, de forma bastante exemplar. A partir do convite que o etnólogo faz ao chefe 
Nambiquara, um deslocamento se realiza para que diferentes grupos desse povo se encontrassem em um lugar estabelecido. Com isso, o grupo que estava com o chefe Nambiquara que fez o acordo com Lévi-Strauss teve que sair de onde acampava, junto a um posto telegráfico em Utiariti, Mato Grosso, e marchar para onde combinaram. Nessa caravana, além dos Nambiquara, também foi a tropa de Lévi-Strauss. O caminho que estabeleceram era difícil e se perderam. Nesse ínterim, tiveram que acampar para esperar o dia clarear, pois havia anoitecido e não teriam como acertar o caminho para seu destino. Assim que raiou o dia, conta-nos Lévi-Strauss:

$\mathrm{Na}$ manhã seguinte, reinava um descontentamento geral, visando ostensivamente o chefe responsabilizado por um negócio que ele e eu tínhamos acertado. Em vez de fazer uma expedição de caça ou de coleta, cada um resolveu se sentar à sombra dos abrigos, e deixaram o chefe encontrar sozinho a solução do problema. Ele sumiu, acompanhado por uma de suas mulheres; à noitinha, vimos os dois voltando, com suas cestas pesadas cheias de gafanhotos que eles haviam passado o dia inteiro colhendo. Embora o patê de gafanhotos não seja um prato muito apreciado, todos comeram com apetite e recobraram seu belo humor (LÉVI-STRAUSS, 2016, p. 314-315).

Com esse exemplo, vemos que o papel de representar seu grupo estava no acordo feito entre o chefe Nambiquara e Lévi-Strauss. Seu papel de não ter poder de mando é visto na falta de imperativos para fazer com que seus companheiros também fossem buscar alimentos. Por fim, servir o grupo com dádivas é visto na ação de ele ter ido buscar alimentos para todos, além, é claro, de ter sido uma das razóes para ele ter feito o acordo com Lévi-Strauss, que entregaria presentes que o chefe poderia distribuir entre os seus.

Vejamos mais de perto uma questão importante impulsionada por essa obrigação do chefe ameríndio à generosidade, mas que se relaciona a questóes da subjetividade desse chefe. É lugar comum, quando se pensa nessas populaçóes não-ocidentais, que se deixe de lado a importância das influências de escolhas pessoais nas questóes que se desenrolam nessas sociedades. Isso se dá, geralmente, pela náo correspondência da noçáo de pessoa à noçáo de individuo, própria do Ocidente, ou seja, por nesses Outros não haver uma associação direta e necessária dessas duas noçóes. Nesse sentido, é comum pensar que as açôes de um sujeito sempre se dariam por implicaçóes sociais, apenas. Entretanto, não é porque não há a noção de indivíduo que não há a noção de pessoa. Esse problema se coloca 
para que tratemos da seguinte questáo: embora o chefe ameríndio seja como que um cativo de sua sociedade, não é por isso que não possua motivaçóes pessoais para realizar seus atos. Para pensarmos sobre isso, vejamos o que acontece quando os grupos Nambiquara finalmente se encontram, no local combinado.

\section{Ler sem significante}

Mesmo não tendo poder efetivo, o chefe ameríndio o é por uma série de qualidades que deve possuir. Para servir a seu povo, deve ter certa geniosidade. Ter uma retórica astuciosa é uma dessas virtudes necessárias para poder desempenhar sua função (CLASTRES, 2013). Como um dos desdobramentos dessa característica, vejamos o que nos conta Lévi-Strauss sobre o momento em que o chefe Nambiquara distribui os presentes para seus companheiros:

Ora, ele reunira todo o seu pessoal, tirou de um cesto um papel coberto de linhas tortuosas que fingiu ler e nas quais procurava, com uma indecisão afetada, a lista dos objetos que eu devia dar em troca dos presentes oferecidos: a este, contra um arco e flechas, uma faca de arrasto! ao outro, contas! para os seus colares... Essa encenação prolongou-se por duas horas. Que esperava ele? Enganar a si mesmo, talvez; mais, porém, surpreender seus companheiros, convencê-los de que tinha participado na escolha das mercadorias, que obtivera a aliança com o branco e que partilhava de seus segredos (LÉVI-STRAUSS, 2016, p. 316).

Para que, entáo, o chefe fazia essa encenação? O que o estimulava a isso? Aqui, Lévi-Strauss sugere que ele assim agira não apenas para desempenhar sua responsabilidade de generosidade, mas talvez a tenha usado como pretexto para uma ambição pessoal:

A escrita fizera, pois, sua aparição entre os Nambiquara; mas não, como se poderia imaginar, ao termo de um trabalhoso aprendizado. Seu símbolo fora imitado, ao passo que sua realidade continuava a ser desconhecida. E isso, com vistas a uma finalidade mais sociológica do que intelectual. Não se tratava de conhecer, reter ou compreender, mas de aumentar o prestígio e a autoridade de um indivíduo - ou de uma função - às custas de outrem (LÉVI-STRAUSS, 2016, p. 317).

A esse respeito, "admite o autor [Lévi-Strauss] que os 'homens não são todos iguais', devendo a individuação psíquica ser levada em conta na designação 
de posiçôes de autoridade" (SZTUTMAN, 2012, p. 314). Com efeito, conclui Lévi-Strauss dizendo que a existência de posiçóes de chefia, geral a todos os grupos humanos, dá-se pois existem alguns sujeitos que "gostam do prestígio em si, sentem-se atraídos pelas responsabilidades, e para quem a carga dos negócios públicos traz consigo sua recompensa" (LÉVI-STRAUSS, 2016, p. 337). Posto isso, convém que falemos de uma característica política das sociedades ameríndias que atuaria como um contrabalanço à possível vontade de um sujeito em posição de chefia exceder a sua função e aspirar ao poder a partir do prestígio que possa ter.

\section{Um grupo que comanda seu chefe}

Levando em conta que as sociedades modernas se organizam, de diferentes formas, a partir do Estado, pode-se afirmar que um de seus princípios basilares se manifesta a partir da divisão da sociedade entre dominantes e dominados. Assim, os chefes dessas sociedades, ao estarem em posição de dominância, comandariam seu grupo. Por sua vez, nas relaçóes ameríndias, em geral, a sociedade se organizaria de outro modo. Elas seriam, então, "sociedades indivisas: [...] sociedades sem divisão em dominantes e dominados - não há órgão separado do poder" (CLASTRES, 2014, p. 141). Ou seja, nessas sociedades, em seu caráter indiviso, não haveria associação do poder a um sujeito ou grupo específico, a sociedade, em si, teria o controle do poder, portanto, o chefe ameríndio náo comandaria seu grupo, mas estaria sob o comando da sociedade a que pertence.

Entre os ameríndios, quando há vestígios de surgimento da dissociação do poder de seu lugar - no seio do próprio grupo -, a sociedade atua para reparar essa disrupção. Esse mecanismo é assim definido por Clastres (2014, p. 142): “[...] com efeito, a política dos selvagens é exatamente opor-se o tempo todo ao aparecimento de um órgáo separado do poder, impedir o encontro de antemáo fatal entre instituição da chefia e exercício do poder”.

Voltemos aos Nambiquara de Lévi-Strauss. Depois da distribuição dos presentes, podemos observar como essa sociedade respondeu à tentativa de seu chefe em obter poder a partir da simulação de compreensão da escrita, em outras palavras, como essa sociedade acionou o mecanismo que a protege da criação de divisão entre dominantes e dominados a partir da atribuição de poder ao chefe. A maioria dos Nambiquara presente nessa cena, desvinculou-se "de seu chefe depois que ele experimentou jogar a cartada da civilização (em seguida à minha visita, foi abandonado pela maioria dos seus)" (LÉVI-STRAUSS, 2016, p. 320). Sobre isso, é importante observar que: 
[...] o chefe está sob vigilância na tribo: a sociedade se preocupa em não deixar o gosto do prestígio transformar-se em desejo de poder. Se o desejo de poder do chefe se torna muito evidente, o procedimento empregado é simples: ele é abandonado ou mesmo morto. $\mathrm{O}$ espectro da divisão talvez assombre a sociedade primitiva, mas ela possui os meios de exorcizá-lo (CLASTRES, 2014, p. 142).

Esse efeito de ilusão, pretendido pelo chefe Nambiquara, e a resposta que essa sociedade dá a essa ação poderiam ser um indício para começarmos a pensar sobre o sistema político-veridictório desse tipo de sociedade, chamada por Clastres de "sociedade contra o Estado". A Semiótica pode oferecer ferramentas para tratarmos disso. Entretanto, antes, seria necessário que essa cena fosse semiotizada.

\section{Semiotizando a Lição de escrita}

O momento político vivido pelos Nambiquara e descrito por Lévi-Strauss no capítulo "Lição de escrita" poderia ser lido como um momento de crise que se desenvolve nessa sociedade. Ora, lê-lo assim ser-nos-ia vantajoso para que pudéssemos entender o sentido que daí se depreende, considerando que os "eventos que antes deste momento de transformação eram mais ou menos previsíveis, tornam-se, nestas circunstâncias extraordinárias, uma espécie de caixa-preta para a interpretação semiótica"3 (ALONSO ALDAMA, 2019, p. 53, tradução nossa). Além disso, seguindo ainda as sugestóes do semioticista Juan Alonso, notamos que a previsibilidade dos desfechos de momentos de crise pode ser uma das características que nos permitiria abordar semioticamente episódios desse tipo. Especificamente no que aconteceu entre os Nambiquara, levando em conta que "a alta semioticidade contida em eventos como esse parecem ser decisivos para a continuação do processo semiótico" ${ }^{4}$ (ALONSO ALDAMA, 2019, p. 53, tradução nossa), ou seja, se observarmos a alta semioticidade contida no ato de tentativa de ilusão realizado pelo chefe Nambiquara, poderíamos vislumbrar uma tendência interpretativa nesse processo político-semiótico. Ser um "incidente extraordinário", como coloca Lévi-Strauss, talvez seja o relevo que nos permitirá pensarmos em seu desdobramento como algo tendencial.

\footnotetext{
3 Texto original: « [...] événements, qui avant ce moment de transformation, se déroulaient de manière plus ou moins prévisible, deviennent dans ces circonstances extraordinaires une sorte de boîte noire de l'interprétation sémiotique. » (ALONSO ALDAMA, 2019, p. 53).

4 «la haute sémioticité de ces mêmes événements, lesquels semblent tous déterminants pour la suite du processus sémiotique. ». (ALONSO ALDAMA, 2019, p. 53).
} 
Para se pensar nos desdobramentos possíveis de certa crise, Alonso nos sugere observarmos os desenvolvimentos e conexóes contidos naquilo que chama de "sinais fracos". Esse conceito

[...] refere-se à informação que normalmente se mostra exteriorizada, prospectiva, mais qualitativa do que quantitativa, que tem uma duração breve e rapidamente se torna obsoleta. São [os sinais fracos] incertos, imprecisos e fragmentados; são pouco significativos se tomados individualmente, e só mostram seu valor se sobrepostos e posicionados em relaçáo com outros sinais ${ }^{5}$ (MEVEL, 2004, p. 174, tradução nossa).

A questão envolvida em um sinal fraco não tem a ver com o quão perceptível ele é. Seria mais relacionada a um indício sensível que pode (ou não) transformar um processo. Logo, o sinal fraco, em si, seria um fato não semiotizado, contido apenas no plano da expressão, servindo como repositório à realização de uma função semiótica (ALONSO ALDAMA, 2019). A isso se deve uma advertência, como o próprio Alonso coloca: não se afirmaria, assim, que o plano de expressáo existe por si só. $\mathrm{O}$ que se póem em destaque é a possibilidade de um ponto de vista semiótico, na reflexão política, que se atente a como a expressividade pode participar de forma decisiva na criação do sentido na política: não é apenas por meio da ideologia que se faz a política, mas também por meio da estética e do estilo.

Levando isso em conta, podemos entender que a ilusão pretendida pelo chefe Nambiquara poderia ser encarada como um sinal fraco, mesmo sendo uma cena tão notável. Acontece que ele seria um sinal fraco se levarmos em conta ser um evento inserido no sistema político desse povo. Nesse sentido, a atuaçáo do chefe poderia ser lida como participante de um paradigma. Assim, o resultado dessa ação poderia se tornar previsível a partir de sua relação com os outros entes paradigmáticos que constituem esse sistema. Ainda sobre o conceito de sinal fraco, para que

[...] faça sentido e pareça a um observador como o modo virtual de existência de uma futura forma semiótica, ele deve poder ser relacionado a outros eventos ou outros sinais que participam de um mesmo sistema.

\footnotetext{
5 « désignent des informations qui sont le plus souvent extraverties, de nature prospective, plus qualitatives que quantitatives, d'une durée de vie limitée et rapidement obsolètes. Elles sont incertaines, imprécises et fragmentaires; peu signifiantes prises individuellement, elles ne s'enrichissent que recoupées et agencées les unes par rapport aux autres » (MEVEL, 2004, p. 174).
} 
Como qualquer sinal ou evento isolado é de difícil interpretação, deve estar inscrito num tipo de relação com outros elementos para que possa assumir um sentido ${ }^{6}$ (ALONSO ALDAMA, 2019, p. 59, tradução nossa).

Levando em conta as ideias de Clastres sobre a política ameríndia e se, de fato, pudermos definir a atitude do chefe Nambiquara como legível dentro do sistema político de seu povo, podemos dizer que a tendência mais esperada em relação à recepção dessa prática por essa sociedade seria a recusa à aceitação de sua perpetuação, como de fato aconteceu. Em outras palavras, esse sinal fraco, por estar contido na lógica política ameríndia, não se estabeleceria como sintagma: a partir da ideia sugerida por Clastres, mais acima, a percepção da ação do chefe com potencial para se tornar sintagmática poderia ser lida como um dos meios que essa sociedade teve de frear o ímpeto de seu chefe à obtenção do poder. Essa ideia pode ser assim resumida: "para detectar uma tendência, por exemplo, o sinal não deve aparecer como um único fato, mas como parte de uma possível série - existente ou futura"7 (ALONSO ALDAMA, 2019, p. 59, tradução nossa). Poderíamos dizer que apesar de ter sido um evento que de fato ocorreu, a ação do chefe Nambiquara não se torna sintagma porque não pode ser inserida na gramática que orienta os paradigmas políticos da sociedade em questão. Foi um erro de escrita.

\section{Uma abertura semiopolítica para compreendermos a nós mesmos: a veridicção na política}

A ideia por trás deste artigo é tentar uma abertura semiopolítica para que possamos enriquecer o nosso conhecimento sobre a existência humana. Para tal intenção, adotamos uma perspectiva antropológica, entendendo que ela permite, pela comparação de fenômenos sociais em diferentes sociedades, vislumbrar padrôes da vida social (LÉVI-STRAUSS, 1985). Nesse sentido, pensamos que a compreensão do evento que fora aqui trabalhado indicaria meios de entendermos os meandros do ponto nevrálgico das relações político-veridictórias em diferentes sociedades, especialmente na relaçáo da chefia (em suas manifestaçóes diversas)

\footnotetext{
${ }_{6}$ «[...] pour qu'un signal faible puisse avoir du sens et apparaître pour un observateur comme le mode d'existence virtuel d'une forme sémiotique à venir, il faut que ce signal puisse être mis en relation avec d'autres événements ou d'autres signaux avec lesquels il feront système. Tout signe ou événement isolé étant difficilement interprétable, il devra être inscrit dans un type de relation avec d'autres éléments pour qu'il puisse accéder au sens ». (ALONSO ALDAMA, 2019, p. 59).

7 " [...] pour qu'on arrive à déceler une tendance par exemple, il faut que le signal n'apparaisse comme un fait unique mais comme un élément d'une série possible - existante ou à venir. »(ALONSO ALDAMA, 2019, p. 59).
} 
com o resto de seu grupo. Com isso em mente, seria possível pensar que reflexão sobre a modalidade veridictória, em casos como esse, poderia ser produtiva. $\mathrm{Ou}$ seja, poderíamos pensar a nossa própria sociedade através da comparaçáo de como outras sociedades reagem a estímulos dessa ordem. Assim, esboçaremos, a seguir, uma reflexão sobre como a modalização veridictória se desenvolveria na cena contida em "Lição de escrita", assumindo que a Semiótica, com essa ferramenta analítica, oferece-nos um amplo potencial comparativo e, com isso, construiríamos uma abertura para uma reflexão comparativa. De uma maneira mais ampla, tentamos estabelecer uma forma de conexão entre a Semiótica e as outras ciências humanas, algo que, desde Greimas, em Semântica estrutural, propóe-se: garantir traduzibilidade entre diferentes semióticas.

A semiótica deveria ocupar, em relação às ciências humanas, o lugar que a língua, segundo Hjelmslev, ocupa frente aos demais sistemas semióticos, e que decorre de sua capacidade de assegurar a traduzibilidade entre os outros sistemas. Essa concepção era igualmente a de Greimas, que atribuía à semiótica a tarefa de propor às ciências humanas uma metalinguagem coerente, já que a semiótica pretende ser uma teoria da significação e as ciências humanas, sob um aspecto ou outro, exploram esta ou aquela ordem de significaçôes. Nesse caso, a função da semiótica não é ditar às ciências humanas suas hipóteses: ela encarrega-se apenas de estabelecer as condições de uma "boa" comunicação entre semiótica geral e semióticas singulares. (FONTANILLE; ZILBERBERG, 2001, p. 55).

A "Lição de escrita" é uma narrativa que fala sobre a jornada do chefe Nambiquara para entrar em conjunção com seu objeto de valor, o poder. Lendo-a assim, podemos notar que a sociedade Nambiquara ocupa a função de destinador-julgador, que acaba sancionando o destinatário - o chefe - a estar em disjunção com o objeto de valor, sançáo imposta pelo rompimento do contrato realizado pelo chefe e que fora tematizado como a perigosa náo realização de alguma obrigação contida na fórmula clássica da chefia ameríndia, como mostrado mais acima.

Por meio da configuração política ameríndia descrita por Clastres, o papel social do chefe Nambiquara o coloca ocupando a posiçáo sintáxica de destinatário de uma narrativa, já que "é colocado em posição de falta de liberdade, ou seja, em posição de não-poder-não-aceitar o contrato proposto" (BARROS, 2001, p. 56). Neste caso, posição de falta de liberdade em relação às imposiçóes colocadas por sua sociedade. A competência para a obtenção do objeto de valor 
pretendido pelo chefe Nambiquara pode ser figurativizada como o aprendizado da função da escrita por esse actante, ao emulá-la a partir da observaçáo do que fazia Lévi-Strauss. A partir da competência adquirida e da realização da performance - figurativizada na tentativa de enganar seus pares -, o chefe recebe, então, sua sanção: como rompe o contrato fiduciário que o obriga a não obter poder por sua posição de chefia, recebe sua punição: é abandonado. Isso se desenrola através de uma modalização veridictória, com o fazer interpretativo da sociedade Nambiquara atuando.

A escrita realizada pelo chefe Nambiquara, assim como foi algo bastante impressionante para Lévi-Strauss, foi, provavelmente, algo impactante para as pessoas de seu grupo. Nesse sentido, poderia ser, em algum instante, algo fracamente inteligível, aproximando-se daquilo que Zilberberg chama de acontecimento. "Como pode nosso chefe ter aprendido isso que os brancos chamam de escrita?”, perguntaria um Nambiquara que testemunha à distribuição dos presentes. Se assim o for, nesse instante de fraca inteligibilidade, a

[...] narratividade, que o acontecimento virtualizou, reclama seus direitos, em compreensão ou em explicaçáo, conforme o estilo persuasivo vigente. De que modo? Considerando o acontecimento como o ponto de chegada cuja origem não é imediatamente identificável (ZILBERBERG, 2011, p. 190).

Ou seja, a escrita do chefe serviria como princípio de investigação para a reconstituição genealógica da inteligibilidade que construiu aquilo que chamamos, mais acima, de sinal fraco. De todo modo, mesmo náo sendo necessariamente um acontecimento, podemos pensar esse momento como algo que invade o campo de presença da sociedade Nambiquara dotado de elá com alta tonicidade e que se instala, em sua incoatividade, como valor de objeto, causando um impacto de novidade no seio do grupo. Gradualmente, então, esse valor se desloca e se torna inteligível na existência Nambiquara, construindo-se como valor de universo, pois aquilo que antes era um ato sensível náo contido no universo cognitivo desse povo - um sinal fraco - torna-se percebido como dotado de conteúdo já existente na esfera política: um chefe que tenta controlar o poder ${ }^{8}$.

\footnotetext{
8 Vale notarmos a importância de situações como esta para a reflexão do político em que o polêmico se torna um fator relevante e vinculado à ordem sensorial, por seu caráter incoativo de alta tonicidade. Esse relevo é dado por, na polêmica, estar contida uma característica sensível forte, despertando uma atenção ao movimento que aí se desenrola. Como nos sugere Alonso, uma das principais razões para isso acontecer é: “a superioridade sensivel, a carga perceptível da disputa, ou seja, sua visibilidade [do polêmico]. O polêmico não só põe a narrativa em
} 
Essa mudança do não inteligível para o inteligível poderia ser entendida como um deslocamento tensivo que se daria pelo deslocamento de acento - do intenso ao extenso - em relação ao efeito de veridicção que aí decorre. Antes de tratarmos desse ponto, faz-se necessário pensarmos na configuração desse efeito de verdade, construído a partir do fazer interpretativo do destinador-julgador - a sociedade Nambiquara - que verifica "a adequação do novo e desconhecido ao velho e já sabido, ou melhor, a um fragmento do universo cognitivo de quem julga” (BARROS, 2001, p. 58). Esse ato modaliza veridictoriamente o destinatário - o chefe - a partir da consideração da manifestação de sua enunciação enunciada - parece ou não-parece - e inferindo sua imanência - é ou não-é (BARROS, 2001). Para pensarmos sobre isso, o quadrado semiótico da veridicção se torna uma ferramenta produtiva. $\mathrm{O}$ ato do chefe - fingir ter o domínio da escrita - poderia, então, ser pensado como algo que / parece/ mas /não-é/, ou seja, ele atua como que para demonstrar o domínio técnico da escrita, quando na verdade ele faz essa encenação como demonstração de poder - ou ao menos vontade de. Além, é claro, do fato de ele não possuir o domínio técnico que finge demonstrar. Por ser algo que /parece/ mas /náo-é/, considera-se, no quadrado semiótico da veridicção, uma ação contida na dêixis da mentira.

Voltemos ao desenvolvimento acentual da cena. Apenas estar modalizada como aquilo que /parece/ mas /não-é/ não permitiria uma compreensão mais refinada da atitude do chefe Nambiquara. Apesar de ser importante levarmos em conta esse caráter descontínuo da cena que aqui semiotizamos, acreditamos que suas características contínuas são de importância fundamental para nossa reflexão, já que trabalhamos com a ideia de que vetores contidos nessa cena apontariam para um devir, ou seja, o sinal fraco de que aqui falamos seria indício de um desdobramento político. Mais: a apreensão da cena possui um movimento. Do ponto de vista dos Nambiquara, é como se ela se iniciasse na não compreensão daquilo que faz o chefe, deslocando-se gradualmente até chegar à apreensão do que se passa, partindo de um momento de alta intensidade para um momento de alta extensidade, configurando uma modulaçáo tensiva caracterizada por uma correlação inversa entre essas duas grandezas. Por isso, observar como o deslocamento acentual se dá, permitir-nos-á entender por quê, nesse povo, a previsibilidade nos indicaria uma tendência mais forte ao grupo abandonar seu chefe. A partir do modo como a enunciação do domínio da escrita nessa cena se dá, nota-se que seu enunciador, o chefe, acentua o valor daquilo que pretende realizar: uma ilusão. Em outras palavras, o chefe aloca o acento da enunciação

movimento, mas também torna as interações que ocorrem no discurso muito mais perceptíveis do que as interações harmônicas ou cordiais" (ALONSO ALDAMA, 2013, p. 21-22). 
no sobrecontrário/parecer/. Entretanto, com o deslocamento tensivo que tornou essa ação inteligível para a sociedade Nambiquara, nota-se que isso acontece pela acentuação dada por estes àquilo considerado imanente a essa ação, no subcontrário /não-ser/. Os Nambiquara notam, então, que a ação fora uma decepção, já que o chefe não honrara o contrato fiduciário estabelecido entre eles. Esse efeito de verdade, a partir da acentuação do /não-ser/, prevaleceria na cena, levando em conta a seguinte premissa: "um estado é considerado verdadeiro quando um outro sujeito, que não o modalizado, o diz verdadeiro” (BARROS, 2001, p. 56). Então, é necessário o fazer interpretativo dos Nambiquara para avaliar se é verdadeira ou não a ação do chefe. Essa modulaçáo tensiva pode ter sua dinâmica sintetizada da seguinte forma: "tudo ocorre como se a grandeza acentuada [...] confiscasse em seu proveito [...] a foria das grandezas [...] desacentuadas" (ZILBERBERG, 2011, p. 290). Aqui, a foria dada pelos Nambiquara não é uma força posterior à enunciação do chefe, mas apenas um deslocamento da euforia que este dá ao sobrecontrário /parecer/ para o subcontrário /não-ser/, a partir da intervenção do grupo.

Sugerimos que refletir em situações como essa, contidas na polêmica, são importantes para pensarmos o político, em qual esfera for. Eventos, se encarados como sinais fracos, podem ser medidos, permitindo-nos vislumbrar os desdobramentos que possuem maior tendência de serem respostas possíveis. Assim, encararíamos um processo que pode, por derivação, dizer-nos sobre alguma orientação do sistema, ou vice-e-versa. Entre uma sociedade contra o Estado como os Nambiquara, a lógica da indivisibilidade em classes certamente nos mostra um espectro de tendências preferidas de respostas geráveis por seu sistema político-veridictório. Aqui, notamos que o destinador-julgador da sociedade é a coletividade, não seu chefe. Então, o destinatário a ser julgado o será a partir dos critérios veridictórios contidos no sistema político desse povo, que se associa de maneira íntima com a forma indivisa desta sociedade. $\mathrm{O}$ mais esperado, então, seria que as sançôes fossem tomadas em relação a esse critério. Seria como se as sançôes se alocassem em um espectro que privilegia a não usurpação do poder por algum actante que entra em relação com o destinador-julgador.

Se a empreitada que realizamos neste artigo tiver uma mínima validade, acreditamos que ela pode servir de inspiração para reflexóes sobre o caráter político-veridictório da sociedade brasileira mais amplamente. Para isso, devemos considerar que a sociedade brasileira não indígena não possui uma divisão política mais complexa em relação à sociedade Nambiquara. A diferença é que no Brasil, tomado como conjunto, há uma divisão política mais especializada. De resto, poderíamos nos atrever a propor alguns problemas a serem pensados 
através dessa comparação. Se os Nambiquara desenvolvem seu sistema político-veridictório por meio de um destinador-julgador que preconiza a não entrega do poder a pessoas específicas, mas pretende mantê-lo em uma forma comunal, como é caracterizado o destinador-julgador da sociedade brasileira a partir da perspectiva não indígena? Quem é o detentor formal do poder? É uma balança entre a miríade de entes que compóem seu sistema político? Como ele atua? $\mathrm{O}$ uso das fake news teve papel importante na delegação do poder no Brasil, levando em conta a eleição de 2018. Por quê, então, a ilusão, enquanto modalização veridictória das fake news, receberia um acento tônico que aí se manteria? Se o fazer interpretativo do sistema político-veridictório Nambiquara tende a disforizar a ilusão ou a mentira, por que no Brasil justamente essa dêixis foi aquela que se sobressaiu?

Como tentamos demonstrar neste artigo, a Semiótica apresenta um grande potencial para a compreensão de problemas da ordem político-veridictória. Nos determos sobre essa característica na sociedade Nambiquara náo foi mais do que um esboço desse tipo de reflexão. Tivemos, aqui, a intenção de desenvolver um exercício que tenta colocar em prática uma possibilidade de análise semiótica que muito pode ajudar outras ciências humanas. Se acreditarmos que há um papel de importância na Semiótica para a leitura de como o humano constrói o sentido do mundo, cabe-nos, agora, tentar construir possibilidades de compreensão que tentem unir essa força contida na leitura semiótica às outras ciências humanas.

\section{REFERÊNCIAS}

ALONSO ALDAMA, J. Crise et imprévisibilité. In: STAY STANGE, V.; HACHETTE, P. ; HORREIN, R. (org.). Sens à l'horizon!: Hommage à Denis Bertrand. Limoges: Lambert-Lucas, 2019. p. 53-60.

ALONSO ALDAMA, J. Desencuentros, malentendidos e incomprensiones. Tópicos del Seminario, Puebla, n.30, p. 17-37, 2013.

BARROS, D. L. P. de. Teoria do discurso: Fundamentos semióticos. São Paulo: Humanitas: FFLCH/USP, 2001.

CLASTRES, P. Arqueologia da violência: pesquisas de antropologia política. Trad. Paulo Neves. São Paulo: Cosac Naify, 2014.

CLASTRES, P. A sociedade contra o Estado: pesquisas de antropologia política. Trad. Theo Santiago. São Paulo: Cosac Naify, 2013. 
FONTANILLE, J.; ZILBERBERG, C. Tensáo e significaçáo. Trad. Ivã Carlos Lopes, Luiz Tatit e Waldir Beividas. São Paulo: Discurso Editorial: Humanitas: FFLCH/USP, 2001.

LÉVI-STRAUSS, C. Tristes trópicos. Trad. Rosa Freire d'Aguiar. São Paulo: Companhia das Letras, 2016.

LÉVI-STRAUSS, C. Antropologia estrutural. Trad. Chaim Samuel Katz e Eginardo Pires. Rio de Janeiro: Tempo Brasileiro, 1985.

MEVEL, O. Du rôle des signaux faibles sur la reconfiguration des processus de la chaîne de valeur de l'organisation: l'exemple d'une centrale d'achats de la grande distribution française. 459f. 2004. Orientador: Pierre Baranger. Tese (Doutorado em Ciências da Gestão) - Université de Bretagne Occidentale, Brest, 2004.

SAUSSURE, F. de. Curso de linguística geral. Trad. Antônio Chelini, José Paulo Paes, Izidoro Blikstein. São Paulo: Cultrix, 2012. Obra original de 1916.

SZTUTMAN, R. O profeta e o principal: a ação política ameríndia e seus personagens. São Paulo: EdUSP: Fapesp, 2012.

ZILBERBERG, C. Elementos de semiótica tensiva. Trad. Ivã Carlos Lopes, Luiz Tatit, Waldir Beividas. São Paulo: Ateliê Editorial, 2011.

Recebido em 11 de maio de 2020.

Aprovado em 07 de julho de 2020. 